\title{
Large Plasmid Complement Resolved: Complete Genome Sequencing of Lactobacillus plantarum MF1298, a Candidate Probiotic Strain Associated with Unfavorable Effect
}

\author{
Anette McLeod ${ }^{1,2} \mathbb{D}$, Annette Fagerlund ${ }^{1}$, Ida Rud ${ }^{1}$ and Lars Axelsson ${ }^{1, * \mathbb{D}}$ \\ 1 Nofima-Norwegian Institute of Food, Fisheries and Aquaculture Research, P.O. Box 210, N-1431 Ås, \\ Norway \\ 2 Center for Laboratory Medicine, Østfold Hospital Trust, P.O. Box 300, N-1714 Grålum, Norway \\ * Correspondence: lars.axelsson@nofima.no
}

Received: 21 June 2019; Accepted: 14 August 2019; Published: 14 August 2019

\begin{abstract}
Considerable attention has been given to the species Lactobacillus plantarum regarding its probiotic potential. L. plantarum strains have shown health benefits in several studies, and even nonstrain-specific claims are allowed in certain markets. L. plantarum strain MF1298 was considered a candidate probiotic, demonstrating in vitro probiotic properties and the ability to survive passage through the human intestinal tract. However, the strain showed an unfavorable effect on symptoms in subjects with irritable bowel syndrome in a clinical trial. The properties and the genome of this strain are thus of general interest. Obtaining the complete genome of strain MF1298 proved difficult due to its large plasmid complement. Here, we exploit a combination of sequencing approaches to obtain the complete chromosome and plasmid assemblies of MF1298. The Oxford Nanopore Technologies MinION long-read sequencer was particularly useful in resolving the unusually large number of plasmids in the strain, 14 in total. The complete genome sequence of 3,576,440 basepairs contains 3272 protein-encoding genes, of which 315 are located on plasmids. Few unique regions were found in comparison with other L. plantarum genomes. Notably, however, one of the plasmids contains genes related to vitamin B12 (cobalamin) turnover and genes encoding bacterial reverse transcriptases, features not previously reported for L. plantarum. The extensive plasmid information will be important for future studies with this strain.
\end{abstract}

Keywords: Lactobacillus plantarum; lactic acid bacterium; probiotic; PacBio sequencing; Illumina sequencing; Oxford Nanopore MinION sequencing; plasmid assembly

\section{Introduction}

Lactobacillus plantarum is one of the most versatile species among lactic acid bacteria (LAB) [1]. Strains of the species are able to colonize a variety of environments including vegetables, meat, dairy substrates and the gastrointestinal (GI) tract [2,3]. There has been considerable interest in the probiotic potential of L. plantarum to maintain and regulate the human intestinal microbiota $[4,5]$, and health benefits have been presented [3,6,7]. L. plantarum belongs to a list of species that has been suggested to be of "general benefit", and for which nonstrain-specific health claims can be made in certain markets [8]. The largest successful clinical trial to date of an oral probiotic preparation was recently reported by Panigrahi et al. [9]. Their findings suggest that a large proportion of neonatal sepsis in developing countries could be effectively prevented using a synbiotic containing L. plantarum ATCC 202195. Although most commercially available probiotic strains are widely regarded as safe, concerns have been raised. Initially, these concerns were mainly with respect to safety in particular populations $[10,11]$. 
Recently, concerns of a more general nature have also been put forward, especially with regard to the effects on the microbiome equilibrium in the GI tract [12]. Published reports of unfavorable effects of probiotics are scarce [12]. L. plantarum strain MF1298, originating from a single colony from Norwegian mutton salami [13], showed promising probiotic potential in early investigations. The strain was confirmed to have antimicrobial activity against potential pathogens, to adhere to the human colon adenoma cell line $\mathrm{CaCo}-2$, and to strengthen transepithelial resistance of a $\mathrm{CaCo}-2$ cell layer with increased production of tight junction proteins $[13,14]$. Tight junctions consist of protein complexes that maintain epithelial barrier integrity, providing an important primary barrier for the intestinal space. The strain was also shown to survive passage through the human GI tract [15]. Despite these suitable properties, an unfavorable effect on symptoms in subjects with irritable bowel syndrome (IBS) was shown after intake of L. plantarum MF1298 in a randomized placebo-controlled crossover trial $[16,17]$. This unfavorable effect manifested itself as a slight, but statistically significant, increase in the standard IBS score. The score is based on a patient's subjective experience of GI function during a treatment compared to a control period, such as "abdominal pain/discomfort", "urgency" and "stool frequency/consistency" [17]. For this reason, the properties and the genome sequence of this strain are interesting, as they may contribute to a broader understanding of probiotics in general and the inspection of genome sequences of candidate probiotic strains with regard to safety and potential undesirable effects.

Whole genome sequencing (WGS) has revolutionized the characterization of bacteria. The sequence of a bacterial genome can be obtained in a very short timeframe and at low costs. However, there are still challenges with regard to obtaining a complete and correctly assembled genome. Bacteria generally harbor a large circular chromosome, and different strains may, in addition, contain one or multiple extrachromosomal plasmids with varying sizes and copy numbers. Plasmids present important genetic engineering tools and are transmission vectors of genes that in nature may benefit the survival of the organism, including resistance to antibiotics, bacteriophages, toxic heavy metals and other stress responses, the production of bacteriocin and exopolysaccharide, and the provision of enzymes that expand the nutritional ability of the cell [18]. The application of short-read sequencing technologies, such as Illumina, to provide WGS data tends to generate incomplete, fragmented genome assemblies, in which differentiation between plasmid and chromosome sequences may be impossible. The correct assembly of the plasmid fraction using short reads is hindered by the presence of high levels of repetitive DNA that is shared between several plasmids and the chromosome [19]. Bacterial plasmids can also span hundreds of kilobases $(\mathrm{kb})$, adding another level of complexity to accurate assembly. Long-read sequencing technologies developed by Pacific Biosciences (PacBio) and Oxford Nanopore Technologies (ONT) overcome many of the limitations researchers face with short reads [20]. However, while standard long-read sequencing protocols often employed in PacBio sequencing include a size selection step that may exclude smaller plasmids [19], nanopore sequencing using ONT platforms has been employed to decipher the structures of smaller plasmids [21,22]. A unique property of the ONT MinION platform is its size, cost, portability, and the real-time utility, where very long reads are rapidly generated [23].

Here, the complete genome sequence of L. plantarum MF1298 is reported, which consists of one circular chromosome and an unusually high number of plasmids: 14 circular plasmids ranging in size from 2.3 to $63.1 \mathrm{~kb}$ were identified. The accurate complete sequence of MF1298 was obtained in a stepwise approach, in which long-read PacBio sequencing was initially used to obtain the sequence of the chromosome and the two largest plasmids. Subsequent short-read Illumina sequencing of the total genomic DNA fraction showed that a substantial amount of plasmid content was lacking from the PacBio assembly. To resolve the plasmid complement, known to often contain genes associated with important functions in LAB strains [18], the plasmid DNA fraction was sequenced using both Illumina and long-read ONT MinION sequencing, and a hybrid assembly was generated using the combined data. 


\section{Materials and Methods}

\subsection{Growth Conditions and DNA Preparation}

L. plantarum MF1298 [13] was cultivated in rich MRS broth (Oxoid, Thermo Fisher Microbiology, Basingstoke, UK) at $37^{\circ} \mathrm{C}$ overnight (still culture). Total genomic DNA was extracted with Advamax beads (Edge BioSystems, Gaithersburg, MD, USA) as detailed elsewhere [24]. The plasmid DNA fraction was purified using the Qiagen Large-Construct Kit (Qiagen, Hilden, Germany)). An additional lysis step was introduced where the cells were incubated at $37^{\circ} \mathrm{C}$ for $10 \mathrm{~min}$ in lysis buffer-added lysozyme (20 mg/mL) (Sigma Aldrich, Steinheim am Albuch, Germany) and mutanolysin (40 U/mL) (Sigma Aldrich). With the plasmid DNA preparation, a sufficient depth of coverage for all plasmids was more likely to be reached, and this strategy therefore avoids omissions from final assembly. The DNA quality was assessed by $0.8 \%$ agarose gel electrophoresis; concentration and purity (A260/A280) were measured using NanoDrop ND-1000 (Thermo Fisher Scientific, Waltham, MA, USA) and Qubit 3 Fluorometer (Thermo Fisher Scientific). DNA samples were preserved at $-20^{\circ} \mathrm{C}$ until further processing.

\subsection{Genome Sequencing and Assembly}

The total genomic DNA preparation was sequenced with PacBio RSII (Pacific Bioscience, Menlo Park, CA, USA) and Illumina MiSeq (San Diego, CA, USA). The RSII library was constructed using the $10 \mathrm{~kb}$-protocol with BluePippin (Sage Science, Beverly, MA, USA) size selection, and sequences were generated using P4-C2 chemistry and two single-molecule real-time (SMRT) cells. An Illumina Nextera XT library was prepared according to the manufacturer's protocols and sequenced using the MiSeq instrument with 300-bp paired-end reads. In total, 58,524 PacBio reads with an average length of $7893 \mathrm{bp}$ were obtained, generating a total number of $462 \mathrm{Mbp}$. The raw reads were filtered prior to de novo assembly using HGAP v2 (Pacific Bioscience). This assembly generated five PacBio contigs, one large $(>3 \mathrm{Mbp})$ and four smaller $(<100 \mathrm{Kbp})$. The two smallest contigs had an average coverage of $<30$, and were excluded from further analysis. The three larger contigs had an average coverage of $>50$ and obvious self-overlapping regions at the beginning and end. Illumina MiSeq sequencing resulted in a total of approximately 13,000,000 good quality pair-end reads, which were used for error correction and confirmation of circularization of the three PacBio contigs using CLC Genomics Workbench v.6.0 (Qiagen). Subsequently, a separate assembly was made from the Illumina reads using CLC Genomics Workbench. The Illumina assembly gave 135 contigs of $>500 \mathrm{bp}$, excluding contigs with coverages of $<100 \times$. The average coverage of contigs mapping to the largest PacBio contig was approximately $1400 \times$.

The plasmid DNA preparation was sequenced by Illumina MiSeq, a Nextera XT library was prepared and sequenced as described above and also by ONT MinION (Oxford Nanopore Technologies, Oxford, UK) sequencing. Two runs were performed on the ONT MinION sequencer using R9.4/FLO-MIN106 flow cells. Sequencing libraries were prepared using the ligation sequencing kit 1D (SQK-LSK108), following the manufacturer's protocols. In the first run, the DNA was sheared by passing through a $21 \mathrm{G}$ needle 20 times, and the library was barcoded using the Native barcoding kit (EXP-NBD103) (Oxford Nanopore Technologies). In the second run, the DNA was sheared to approximately 8000-kb fragments in a g-TUBE (Covaris, Brighton, UK). Raw nanopore fast5 reads were base-called using ONT-Albacore v.2.0.2 (Oxford Nanopore Technologies), and adapters were removed using Porechop v.0.2.2 (Oxford Nanopore Technologies). For the reads from the barcoded library, both ONT-Albacore and Porechop were run with barcode demultiplexing. A total of 954,040 good quality pair-end Illumina reads and 26,690 nanopore reads $>1 \mathrm{~kb}$ (mean read length of $5880 \mathrm{bp}$ ) were assembled using the Unicycler v.0.3.0b hybrid assembly pipeline [25], resulting in 12 distinct closed circular plasmids. 


\subsection{Genomic Analysis}

Genomic features were identified and annotated using the NCBI Prokaryotic Annotation Pipeline (PGAP) [26]. Chromosome alignments between MF1298 and five other L. plantarum strains were performed using the progressive MAUVE algorithm of the MAUVE software [27] with default options. The strains used were (GenBank no.): L. plantarum WCFS1 (AL935263.2), L. plantarum TMW 1.1623 (CP017379.1), L. plantarum ZJ316 (CP004082.1), L. plantarum KP (CP013749.1) and L. plantarum subsp. argentoratensis DSM $16365^{\mathrm{T}}$ (CP032751.1). The chromosome DNA sequences were arranged to have the same orientation and start position (gene $d n a A$ ) before alignment.

Plasmids and selected chromosomal sequence regions were subjected to homology searches using BLAST [28]. In some instances, genomic features were identified and annotated using the Rapid Annotation Search Tool (RAST) [29] to complement the PGAP annotation.

\section{Results and Discussion}

\subsection{Genome Characteristics}

The initial total genomic DNA sequencing with PacBio and Illumina MiSeq strategies yielded three circular units, one large circular chromosome of 3,235,952 bp and two plasmids of 63,114 bp and $55,699 \mathrm{bp}$ (Table 1). The first version of the genome assembly (GenBank no. GCA_001880185.1) also contained 26 linear contigs originating from a separate Illumina assembly, in which contigs mapping to the three PacBio units were excluded, and a contig-size cutoff of $1000 \mathrm{bp}$ was used. The total length of the 26 contigs was 209,814 bp, showing that a considerable part of the plasmid DNA was not captured or assembled correctly using the PacBio approach. The Illumina assembly alone was, however, too fragmented to resolve these sequences into circular units. To resolve the plasmid fraction, we therefore applied a hybrid approach with Illumina MiSeq and ONT MinION sequencing of a plasmid DNA-enriched fraction. Indeed, this hybrid assembly of nanopore long-reads and Illumina short-reads yielded 12 circular plasmids that ranged in size from 2273 to $47,476 \mathrm{bp}$ (Table 1). 
Table 1. Genome features of Lactobacillus plantarum MF1298.

\begin{tabular}{|c|c|c|c|c|c|c|c|c|c|c|c|c|}
\hline GenBank Assembly * & $\begin{array}{c}\text { GenBank } \\
\text { No. }\end{array}$ & Type & Name & Topology & Size (bp) & GC\% & Protein & rRNA & tRNA & $\begin{array}{l}\text { Other } \\
\text { RNA }\end{array}$ & Gene & $\begin{array}{c}\text { Pseudo } \\
\text { Gene }\end{array}$ \\
\hline \multirow{3}{*}{$\begin{array}{l}\text { GCA_001880185.1 and } \\
\text { GCA_001880185.2 }\end{array}$} & СР013149.1 & Chromosome & MF1298 & Circular & 3235952 & 44.6 & 2957 & 16 & 69 & 4 & 3118 & 72 \\
\hline & СР013150.1 & Plasmid & pMF1298-1 & Circular & 63114 & 41.1 & 60 & - & - & - & 71 & 11 \\
\hline & СР013151.1 & Plasmid & pMF1298-2 & Circular & 55699 & 40.1 & 50 & - & - & - & 58 & 8 \\
\hline \multirow{12}{*}{ GCA_001880185.2 } & СР013153.2 & Plasmid & pMF1298-3 & Circular & 47476 & 40.7 & 40 & - & - & - & 47 & 7 \\
\hline & СР013152.2 & Plasmid & pMF1298-4 & Circular & 45064 & 40.8 & 35 & - & - & - & 49 & 14 \\
\hline & СР013155.2 & Plasmid & pMF1298-5 & Circular & 37426 & 40.7 & 33 & - & - & - & 38 & 5 \\
\hline & СР013156.2 & Plasmid & pMF1298-6 & Circular & 30526 & 45.8 & 29 & - & - & - & 35 & 6 \\
\hline & СР013154.2 & Plasmid & pMF1298-7 & Circular & 23493 & 39.6 & 21 & - & - & - & 29 & 8 \\
\hline & СР013158.2 & Plasmid & pMF1298-8 & Circular & 10848 & 36.5 & 14 & - & - & - & 17 & 3 \\
\hline & СР013160.2 & Plasmid & pMF1298-9 & Circular & 8511 & 34.2 & 10 & - & - & - & 10 & - \\
\hline & СР013166.2 & Plasmid & pMF1298-10 & Circular & 5636 & 36.3 & 9 & - & - & - & 11 & 2 \\
\hline & СР013162.2 & Plasmid & pMF1298-11 & Circular & 4130 & 37.7 & 4 & - & - & - & 4 & - \\
\hline & СР013167.2 & Plasmid & pMF1298-12 & Circular & 3350 & 38.4 & 4 & - & - & - & 4 & - \\
\hline & СР013168.2 & Plasmid & pMF1298-13 & Circular & 2942 & 35.8 & 3 & - & - & - & 5 & 2 \\
\hline & СР013170.2 & Plasmid & pMF1298-14 & Circular & 2273 & 36.6 & 3 & - & - & - & 3 & - \\
\hline
\end{tabular}

* The initial version 1 (GCA_001880185.1) of the genome assembly was based on PacBio and Illumina sequencing data of total genomic DNA and consisted of 29 entities. It included three circular units, one large chromosome and two plasmids, as well as 26 linear contigs (the linear contigs are not indicated in this table). The three circular units remain unchanged in the second version (Version 2; GCA_001880185.2), consisting of 15 entities, which included MinION and Illumina sequencing data of a plasmid DNA-enriched fraction, which facilitated the recovery of complete plasmid structures. 
The large plasmids obtained from PacBio sequencing were poorly represented in this plasmid fraction, possibly reflecting the generally recognized problem of recovering large plasmids with standard plasmid enrichment procedures [30]. General genome features are presented in Table 1 and approximate read coverages listed in Table S1. The size of the complete L. plantarum MF1298 genome was 3,576,440 bp in total. This is one of the largest complete genomes described so far for L. plantarum, and the plasmid complement is the largest, both in the number of plasmids (14) and the bp content $(340,488)$. Previously, L. plantarum strain 16 harbored the largest plasmid complement reported for this species, involving 10 plasmids (pLp16A-pLp16L), which ranged in size from 6.46 to $74.08 \mathrm{~kb}$ [31]. The GC content of the complete genome was $44.2 \%$, with the chromosome specifically at $44.6 \%$, similar to other L. plantarum strains. The plasmids generally had significantly lower GC content (Table 1), indicating that these might originate from horizontal gene transfer (HGT) events [32]. The plasmids contribute 315 protein-encoding genes to L. plantarum MF1298 and increase the total genomic content by $10.5 \%$.

MAUVE alignments between the MF1298 chromosome and a large number of other complete L. plantarum chromosomes were performed, and a high degree of synteny could be seen between the chromosome of MF1298 and that of the other strains (not shown). We carefully selected five of the complete chromosomes of the subspecies plantarum, which included a standard reference strain (strain WCFS1 [33,34]), one of the largest L. plantarum chromosomes to date (the insect strain KP [35]), and two strains (TMW 1.1623 and ZJ316) that represent genomes at different distances from MF1298 in the phylogeny of L. plantarum genomes as presented by NCBI [36]. Finally, we also included the complete chromosome of a strain representing an example of the subspecies argentoratensis (DSM 16365 ${ }^{\mathrm{T}}$ ). The high degree of synteny between the chromosome of MF1298 and that of the other strains is clearly illustrated (Figure 1), as well as a high similarity within each local collinear block (LCB). MF1298 has an inversion compared to the other strains in the so-called Lifestyle Adaptation Region [33] near the end of the linear representation of the chromosome (position approximately 3,100,000), and contains a few unique regions in comparison with the five other strains. However, BLAST homology searches revealed that the genes present in these regions are found in other L. plantarum strains not included in this comparison (not shown), and are therefore not unique for the species as a whole. As observed previously [1], the larger unique regions found in all strains often represent different prophages. The chromosome from strain DSM $16365^{\mathrm{T}}$, representing the subspecies argentoratensis, appeared most divergent from the others, which was expected and also noted by others [1]. 


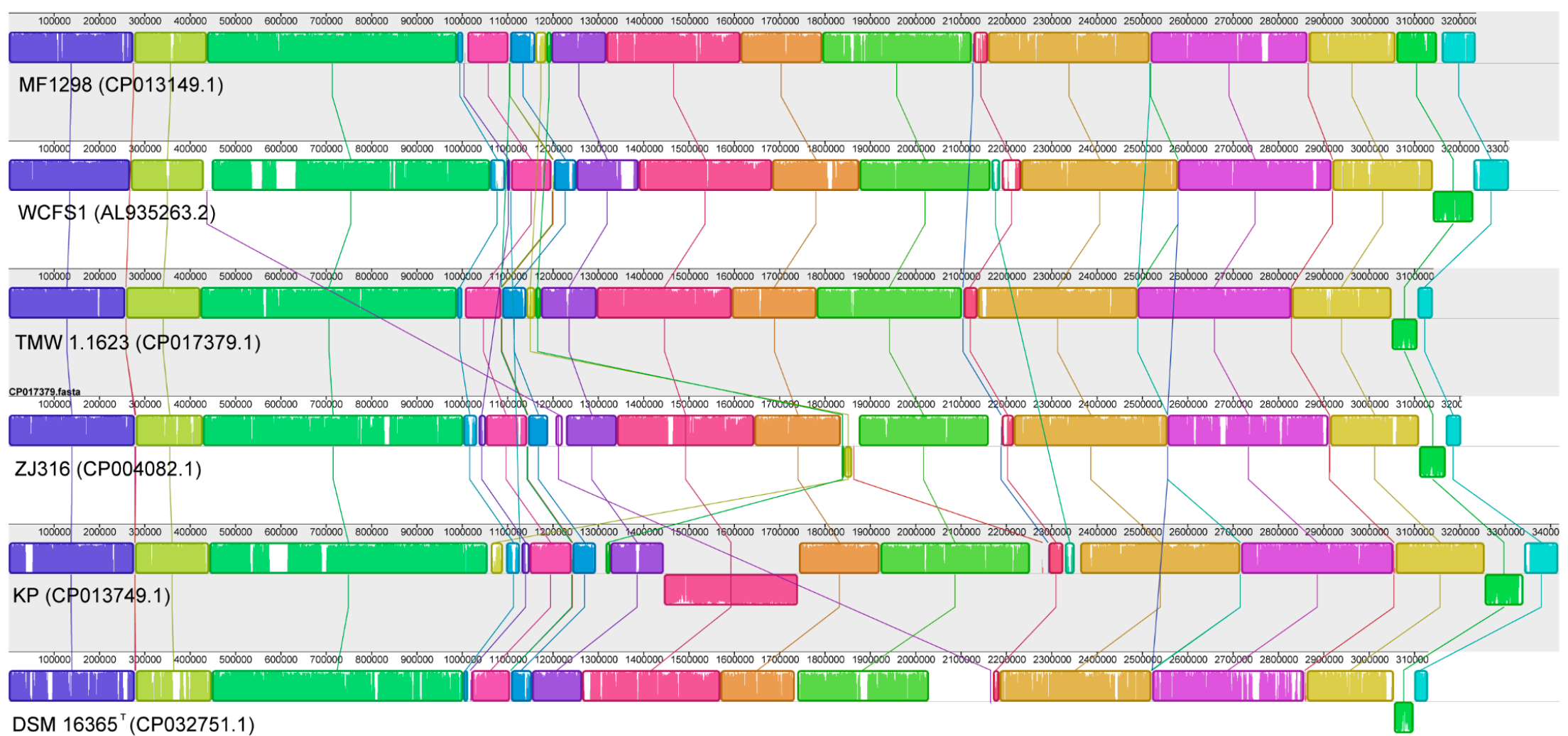

Figure 1. Chromosomal alignment of six Lactobacillus plantarum strains. The alignment was performed using MAUVE software [27] with strain MF1298 set as the reference. Each contiguously colored region is a local collinear block (LCB), a region without rearrangement of homologous backbone sequence. LCBs below the center line of a chromosome are in the reverse complement orientation relative to the reference chromosome. Lines between genomes trace each orthologous LCB through every chromosome. The white areas inside each LCB show regions with low similarities. Regions outside LCBs represent unique regions. 


\subsection{The Plasmid Complement}

Plasmid maps of pMF1298-1 to -14 are presented in the Supplementary Materials (Figure S1). Inferred by homology using BLAST [28], the four smallest plasmids (pMF1298-11 to -14) appear to have a rolling-circle (RC) type of replication, with replication genes (rep) similar to published L. plantarum plasmids [37]. The other plasmids most likely have a theta type of replication, showing rep-regions with homology to either known L. plantarum plasmids [38] or to the same family as pAD1 or $\mathrm{PAM} \beta 1$ archetypal conjugative enterococcal plasmids [39]. Accordingly, some of the larger plasmids contain genes encoding putative functions involved in conjugal transfer and mobilization. Putative mobilization genes were also represented in some of the smaller plasmids. Coverage data from the initial Illumina MiSeq assembly of total genomic DNA (Table S1) indicated copy numbers of 8-12 chromosome equivalents for the RC plasmids. The other plasmids have considerably lower copy numbers $(<4)$. Note that the Illumina sequencing coverage data of the plasmid-enriched fraction showed the same, even more pronounced, division of high- and low-copy number plasmids (Table S1). In this case, plasmid enrichment may have introduced a bias towards higher recovery of the smaller, high-copy number plasmids. Most of the genes encoded by the MF1298 plasmids have homologues in other L. plantarum strains; however, the similarities are limited to relatively short stretches of homology. In many cases, contiguous stretches of homologous gene sequences are interrupted by transposable elements and/or recombinase genes (approximately 50) scattered among the plasmids (Figure S1). This creates composite or mosaic structures, which has been noticed for L. plantarum plasmids previously [38]. An example of this is shown in more detail for plasmid pMF1298-5 (Figure 2).

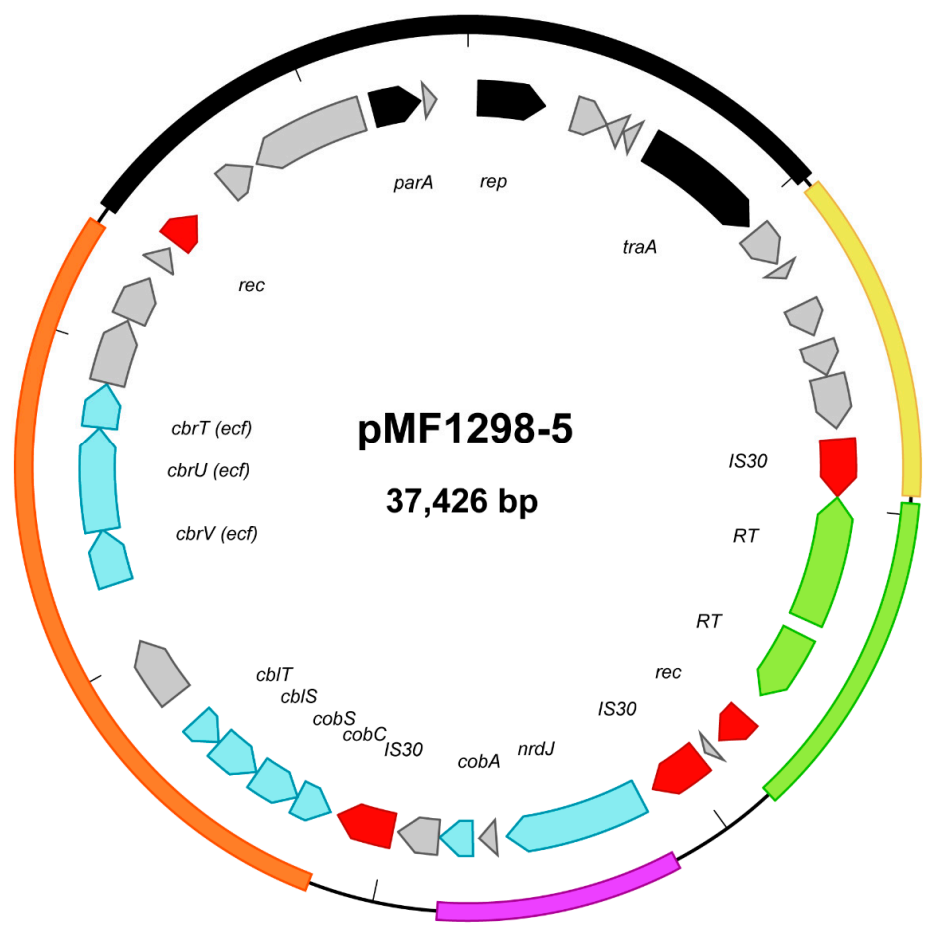

Figure 2. Lactobacillus plantarum plasmid pMF1298-5 displays a mosaic structure with regions of different origins flanked by transposases/recombinases: L. plantarum rep/parA (replication and partition) and tra (conjugal transfer) region (black), L. plantarum and Pediococcus plasmids (yellow), Pediococcus parvulus retron (reverse transcriptase; RT) region (green), L. buchneri/L. brevis nrdJ/cobA region (purple), L. brevis cobalamin region (orange). Genes related to cobalamin turnover are depicted in light blue and transposase/recombinase genes in red. Genes not annotated in this illustration are shown in grey (a majority of these encode hypothetical proteins). See text for further details. Annotations of the genes are based on RAST [29] and BLAST [28] homology searches in addition to the primary PGAP annotation (GenBank no. CP013155.2). 
Thus, the picture that emerges is of a strain that has acquired a substantial amount of extrachromosomal elements through HGT, followed by extensive rearrangements mediated by an array of transposons/recombinases, and in addition may have the capability to act as a donor for new HGT events through conjugation and mobilization. This reinforces the notion that L. plantarum represents an example of a nomadic bacterial species that is characterized by its dynamic and flexible lifestyle [2], and where the plasmid biology may play an important, possibly underestimated, role. The sheer amount of plasmid DNA and the combination of genes thus acquired define some of the uniqueness of strain MF1298. In addition, and in contrast to the chromosome, plasmid pMF1298-5 (Figure 2) contains regions that appear to be unique for MF1298 compared to other L. plantarum strains. These regions contain genes putatively encoding functions related to vitamin B12 (cobalamin) turnover: a coenzyme B12 dependent ribonucleotide reductase ( $\mathrm{NrdJ}$ ), $\mathrm{Cob}(\mathrm{I})$ alamin adenosyltransferase (CobA), an operon encoding homologues to the proteins $\mathrm{CblT}, \mathrm{CblS}$, CobS, and $\mathrm{CobC}$, which are related to a salvage pathway for cobalamin synthesis [40], and an ECF transporter (CbrV, CbrU, CbrT) [41]. Providing appropriate precursors are available, this may enable strain MF1298 to produce cobalamin. Interestingly, an adjacent region in this plasmid includes genes encoding two retron-type reverse transcriptases [42], also unique among L. plantarum strains, indicating the presence of yet another type of mechanism that might increase the flexibility of the genome. Also worthy of note, and due to its plasmid complement, strain MF1298 seems particularly well equipped for heavy-metal resistance. Two identical copies of the arsenate and cadmium resistance gene operon (ars/cad), known from a plasmid of the reference strain L. plantarum WCFS1 [43], are present on pMF1298-1 and pMF1298-2. In addition, other genes putatively related to heavy-metal resistance are present on pMF1298-4, pMF1298-6 and pMF1298-7 (Figure S1).

\subsection{Probiotic Potential}

Despite being shown to have suitable probiotic properties in vitro and to survive passage through the human intestinal tract [13-15], L. plantarum MF1298 was associated with an unfavorable effect on symptoms in subjects with IBS when tried as a candidate probiotic $[16,17]$. Our genome analysis supported some of the potential probiotic properties of the strain. For example, genes encoding large surface proteins or extracellular matrix-binding proteins, such as mucus- or collagen-binding proteins (e.g., protein_IDs APD01026.1, APD01681.1, APD01745.1, and AXN90884.1), which might enable bacterial attachment to eukaryotic epithelial cells, were identified. Some of these were plasmid-encoded. Although difficult to evaluate from genome data only, this initial investigation did not reveal obvious genome features that can explain the unfavorable effect found in the clinical trial.

Since the IBS diagnosis is based on subjective patient experience, such as "abdominal pain", and not measurements of specific physiological parameters, speculations on which genes might be involved in creating aggravated symptoms become difficult. MF1298 did not show any unusual antibiotic resistance pattern in a simple phenotypic test performed prior to the clinical trial (unpublished observations). This was confirmed in this work as no antibiotic resistance genes were identified. Similarly, no virulence factors were found. Except for a version of the plantaricin operon in the chromosome, present in most L. plantarum strains [1,2], bacteriocin genes were also not identified.

\section{Conclusions}

In all, information on the whole genome sequence of L. plantarum MF1298 presented here will be useful for further studies of this strain for evaluating its properties in relation to genome content. Further investigations on strain MF1298 may also contribute to a deeper understanding of which genes and corresponding properties may define a probiotic and/or may constitute a possible safety concern. Considering the high genetic versatility of the L. plantarum species [1,2], it is valuable to increase the number of sequenced strains to account for the genetic variability and their association with specific features like probiotic potential. Such studies should include complete assemblies of the plasmid 
content since, as shown for strain MF1298, as much as 10\% of the genome content, as well as unique features, could be located on plasmids.

Supplementary Materials: The following are available online at http://www.mdpi.com/2076-2607/7/8/262/s1, Table S1: Sequence coverage, Figure S1: Lactobacillus plantarum plasmids pMF1298-1 to -14.

Author Contributions: Conceptualization, L.A. and I.R.; methodology, A.F. and L.A.; validation, A.M., A.F. and L.A.; formal analysis, A.M., A.F. and L.A.; investigation, A.M., L.A. and A.F.; resources, L.A.; data curation, A.M., A.F. and L.A.; writing —original draft preparation, A.M.; writing—review and editing, A.M., A.F., I.R. and L.A.; visualization, A.M., A.F. and L.A.; supervision, L.A.; project administration, L.A.; funding acquisition, L.A.

Funding: This work was funded by the Norwegian Fund for Research Fees for Agricultural Products (project: Nofima 201704), and by the SysMO-LAB2 project financed by the Research Council of Norway (grant no. 203128 under the ERASysBio ERA-NET umbrella).

Acknowledgments: Sequencing of the total genomic DNA was performed at the Norwegian Sequencing Centre (www.sequencing.uio.no). We thank Merete Rusås Jensen and Signe Marie Drømtorp for excellent technical assistance.

Conflicts of Interest: The authors declare no conflict of interest. The funders had no role in the design of the study; in the collection, analyses, or interpretation of data; in the writing of the manuscript, or in the decision to publish the results.

\section{References}

1. Siezen, R.J.; Tzeneva, V.A.; Castioni, A.; Wels, M.; Phan, H.T.; Rademaker, J.L.; Starrenburg, M.J.; Kleerebezem, M.; Molenaar, D.; van Hylckama Vlieg, J.E. Phenotypic and genomic diversity of Lactobacillus plantarum strains isolated from various environmental niches. Environ. Microbiol. 2010, 12, 758-773. [CrossRef] [PubMed]

2. Martino, M.E.; Bayjanov, J.R.; Caffrey, B.E.; Wels, M.; Joncour, P.; Hughes, S.; Gillet, B.; Kleerebezem, M.; van Hijum, S.A.; Leulier, F. Nomadic lifestyle of Lactobacillus plantarum revealed by comparative genomics of 54 strains isolated from different habitats. Environ. Microbiol. 2016, 18, 4974-4989. [CrossRef] [PubMed]

3. Siezen, R.J.; van Hylckama Vlieg, J.E. Genomic diversity and versatility of Lactobacillus plantarum, a natural metabolic engineer. Microb. Cell Fact. 2011, 10, S3. [CrossRef] [PubMed]

4. Connelly, P. Lactobacillus plantarum-A literature review of therapeutic benefits. J. Aust. Tradit. Med. Soc. 2008, 14, 79-82.

5. Klarin, B.; Molin, G.; Jeppsson, B.; Larsson, A. Use of the probiotic Lactobacillus plantarum 299 to reduce pathogenic bacteria in the oropharynx of intubated patients: A randomised controlled open pilot study. Crit. Care 2008, 12, R136. [CrossRef]

6. Cebeci, A.; Gurakan, C. Properties of potential probiotic Lactobacillus plantarum strains. Food Microbiol. 2003, 20, 511-518. [CrossRef]

7. de Vries, M.C.; Vaughan, E.E.; Kleerebezem, M.; de Vos, W.M. Lactobacillus plantarum-Survival, functional and potential probiotic properties in the human intestinal tract. Int. Dairy J. 2006, 16, 1018-1028. [CrossRef]

8. Hill, C.; Guarner, F.; Reid, G.; Gibson, G.R.; Merenstein, D.J.; Pot, B.; Morelli, L.; Canani, R.B.; Flint, H.J.; Salminen, S.; et al. Expert consensus document. The International Scientific Association for Probiotics and Prebiotics consensus statement on the scope and appropriate use of the term probiotic. Nat. Rev. Gastroenterol. Hepatol. 2014, 11, 506-514. [CrossRef]

9. Panigrahi, P.; Parida, S.; Nanda, N.C.; Satpathy, R.; Pradhan, L.; Chandel, D.S.; Baccaglini, L.; Mohapatra, A.; Mohapatra, S.S.; Misra, P.R.; et al. A randomized synbiotic trial to prevent sepsis among infants in rural India. Nature 2017, 548, 407-412. [CrossRef]

10. Boyle, R.J.; Robins-Browne, R.M.; Tang, M.L.K. Probiotic use in clinical practice: What are the risks? Am. J. Clin. Nutr. 2006, 83, 1256-1264. [CrossRef]

11. Spiller, R. Review article: Probiotics and prebiotics in irritable bowel syndrome. Aliment. Pharmacol. Ther. 2008, 28, 385-396. [CrossRef] [PubMed]

12. Lerner, A.; Shoenfeld, Y.; Matthias, T. Probiotics: If it does not help it does not do any harm. Really? Microorganisms 2019, 7, 104. [CrossRef] [PubMed] 
13. Klingberg, T.D.; Axelsson, L.; Naterstad, K.; Elsser, D.; Budde, B.B. Identification of potential probiotic starter cultures for Scandinavian-type fermented sausages. Int. J. Food Microbiol. 2005, 105, 419-431. [CrossRef] [PubMed]

14. Klingberg, T.D.; Pedersen, M.H.; Cencic, A.; Budde, B.B. Application of measurements of transepithelial electrical resistance of intestinal epithelial cell monolayers to evaluate probiotic activity. Appl. Environ. Microbiol. 2005, 71, 7528-7530. [CrossRef] [PubMed]

15. Klingberg, T.D.; Budde, B.B. The survival and persistence in the human gastrointestinal tract of five potential probiotic lactobacilli consumed as freeze-dried cultures or as probiotic sausage. Int. J. Food Microbiol. 2006, 109, 157-159. [CrossRef]

16. Farup, P.G.; Jacobsen, M.; Ligaarden, S.C.; Rudi, K. Probiotics, symptoms, and gut microbiota: What are the relations? A randomized controlled trial in subjects with irritable bowel syndrome. Gastroenterol. Res. Pract. 2012, 2012, 214102. [CrossRef]

17. Ligaarden, S.; Axelsson, L.; Naterstad, K.; Lydersen, S.; Farup, P. A candidate probiotic with unfavourable effects in subjects with irritable bowel syndrome: A randomised controlled trial. BMC Gastroenterol. 2010, 10, 16. [CrossRef]

18. Cui, Y.; Hu, T.; Qu, X.; Zhang, L.; Ding, Z.; Dong, A. Plasmids from food lactic acid bacteria: Diversity, similarity, and new developments. Int. J. Mol. Sci. 2015, 16, 13172-13202. [CrossRef]

19. Arredondo-Alonso, S.; Willems, R.J.; van Schaik, W.; Schürch, A.C. On the (im)possibility of reconstructing plasmids from whole-genome short-read sequencing data. Microb. Genom. 2017, 3, e000128. [CrossRef]

20. Koren, S.; Phillippy, A.M. One chromosome, one contig: Complete microbial genomes from long-read sequencing and assembly. Curr. Opin. Microbiol. 2015, 23, 110-120. [CrossRef]

21. George, S.; Pankhurst, L.; Hubbard, A.; Votintseva, A.; Stoesser, N.; Sheppard, A.E.; Mathers, A.; Norris, R.; Navickaite, I.; Eaton, C.; et al. Resolving plasmid structures in Enterobacteriaceae using the MinION nanopore sequencer: Assessment of MinION and MinION/Illumina hybrid data assembly approaches. Microb. Genom. 2017, 3, e000118. [CrossRef] [PubMed]

22. Wick, R.R.; Judd, L.M.; Gorrie, C.L.; Holt, K.E. Completing bacterial genome assemblies with multiplex MinION sequencing. Microb. Genom. 2017, 3, e000132. [CrossRef] [PubMed]

23. Jain, M.; Olsen, H.E.; Paten, B.; Akeson, M. The Oxford Nanopore MinION: Delivery of nanopore sequencing to the genomics community. Genome Biol. 2016, 17, 239. [CrossRef] [PubMed]

24. Aakra, A.; Nyquist, O.L.; Snipen, L.; Reiersen, T.S.; Nes, I.F. Survey of genomic diversity among Enterococcus faecalis strains by microarray-based comparative genomic hybridization. Appl. Environ. Microbiol. 2007, 73, 2207-2217. [CrossRef] [PubMed]

25. Wick, R.R.; Judd, L.M.; Gorrie, C.L.; Holt, K.E. Unicycler: Resolving bacterial genome assemblies from short and long sequencing reads. PLoS Comp. Biol. 2017, 13, e1005595. [CrossRef] [PubMed]

26. Tatusova, T.; DiCuccio, M.; Badretdin, A.; Chetvernin, V.; Nawrocki, E.P.; Zaslavsky, L.; Lomsadze, A.; Pruitt, K.D.; Borodovsky, M.; Ostell, J. NCBI prokaryotic genome annotation pipeline. Nucl. Acids Res. 2016, 44, 6614-6624. [CrossRef]

27. Darling, A.E.; Mau, B.; Perna, N.T. progressiveMauve: Multiple Genome Alignment with Gene Gain, Loss and Rearrangement. PLoS ONE 2010, 5, e11147. [CrossRef]

28. Camacho, C.; Coulouris, G.; Avagyan, V.; Ma, N.; Papadopoulos, J.; Bealer, K.; Madden, T.L. BLAST+: Architecture and applications. BMC Bioinform. 2009, 10, 421. [CrossRef]

29. Aziz, R.K.; Bartels, D.; Best, A.A.; DeJongh, M.; Disz, T.; Edwards, R.A.; Formsma, K.; Gerdes, S.; Glass, E.M.; Kubal, M.; et al. The RAST server: Rapid annotations using subsystems technology. BMC Genom. 2008, 9. [CrossRef]

30. Conlan, S.; Thomas, P.J.; Deming, C.; Park, M.; Lau, A.F.; Dekker, J.P.; Snitkin, E.S.; Clark, T.A.; Luong, K.; Song, Y.; et al. Single-molecule sequencing to track plasmid diversity of hospital-associated carbapenemase-producing Enterobacteriaceae. Sci. Transl. Med. 2014, 6, 254ra126. [CrossRef]

31. Crowley, S.; Bottacini, F.; Mahony, J.; van Sinderen, D. Complete genome sequence of Lactobacillus plantarum strain 16, a broad-spectrum antifungal-producing lactic acid bacterium. Genome Announc. 2013, 1. [CrossRef] [PubMed]

32. Ravenhall, M.; Škunca, N.; Lassalle, F.; Dessimoz, C. Inferring horizontal gene transfer. PLoS Comp. Biol. 2015, 11, e1004095. [CrossRef] [PubMed] 
33. Kleerebezem, M.; Boekhorst, J.; van Kranenburg, R.; Molenaar, D.; Kuipers, O.P.; Leer, R.; Tarchini, R.; Peters, S.A.; Sandbrink, H.M.; Fiers, M.W.E.J.; et al. Complete genome sequence of Lactobacillus plantarum WCFS1. Proc. Natl. Acad. Sci. USA 2003, 100, 1990-1995. [CrossRef] [PubMed]

34. Siezen, R.J.; Francke, C.; Renckens, B.; Boekhorst, J.; Wels, M.; Kleerebezem, M.; van Hijum, S.A. Complete resequencing and reannotation of the Lactobacillus plantarum WCFS1 genome. J. Bacteriol. 2012, 194, 195-196. [CrossRef] [PubMed]

35. Petkau, K.; Fast, D.; Duggal, A.; Foley, E. Comparative evaluation of the genomes of three common Drosophila-associated bacteria. Biol. Open 2016, 5, 1305. [CrossRef]

36. NCBI. Organism Overview; Lactobacillus plantarum-Common Gastrointestinal Bacterium Used in Food Production. Available online: https://www.ncbi.nlm.nih.gov/genome/?term=lactobacillus+plantarum+wcfs1 (accessed on 25 May 2019).

37. Cho, G.S.; Huch, M.; Mathara, J.M.; van Belkum, M.J.; Franz, C.M.A.P. Characterization of pMRI 5.2, a rolling-circle-type plasmid from Lactobacillus plantarum BFE 5092 which harbours two different replication initiation genes. Plasmid 2013, 69, 160-171. [CrossRef] [PubMed]

38. Danielsen, M. Characterization of the tetracycline resistance plasmid pMD5057 from Lactobacillus plantarum 5057 reveals a composite structure. Plasmid 2002, 48, 98-103. [CrossRef]

39. Paulsen, I.T.; Banerjei, L.; Myers, G.S.A.; Nelson, K.E.; Seshadri, R.; Read, T.D.; Fouts, D.E.; Eisen, J.A.; Gill, S.R.; Heidelberg, J.F.; et al. Role of mobile DNA in the evolution of vancomycin-resistant Enterococcus faecalis. Science 2003, 299, 2071-2074. [CrossRef]

40. Gray, M.J.; Escalante-Semerena, J.C. A new pathway for the synthesis of $\alpha$-ribazole-phosphate in Listeria innocua. Mol. Microbiol. 2010, 77, 1429-1438. [CrossRef]

41. Rodionov, D.A.; Hebbeln, P.; Eudes, A.; ter Beek, J.; Rodionova, I.A.; Erkens, G.B.; Slotboom, D.J.; Gelfand, M.S.; Osterman, A.L.; Hanson, A.D.; et al. A novel class of modular transporters for vitamins in prokaryotes. J. Bacteriol. 2009, 191, 42-51. [CrossRef]

42. Toro, N.; Nisa-Martínez, R. Comprehensive phylogenetic analysis of bacterial reverse transcriptases. PLoS ONE 2014, 9, e114083. [CrossRef] [PubMed]

43. van Kranenburg, R.; Golic, N.; Bongers, R.; Leer, R.J.; de Vos, W.M.; Siezen, R.J.; Kleerebezem, M. Functional analysis of three plasmids from Lactobacillus plantarum. Appl. Environ. Microbiol. 2005, 71, 1223-1230. [CrossRef] [PubMed] 